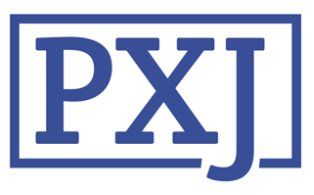

Patient Experience Journal

Volume 2 | Issue 1

Article 8

2015

\title{
The Children's Hospital of Philadelphia Family Partners Program: Promoting child and family-centered care in pediatrics
}

Amy Kratchman, BA

The Children's Hospital of Philadelphia

Darlene Barkman, MA

The Children's Hospital of Philadelphia

Kathy Conaboy, BA

The Children's Hospital of Philadelphia

Anna de la Motte, MSed

The Children's Hospital of Philadelphia

Rachel Biblow, MSW

The Children's Hospital of Philadelphia

See next page for additional authors

Follow this and additional works at: https://pxjournal.org/journal

Part of the Health and Medical Administration Commons, Health Policy Commons, Health Services Administration Commons, and the Health Services Research Commons

\section{Recommended Citation}

Kratchman, BA A, Barkman, MA D, Conaboy, BA K, de la Motte, MSed A, Biblow, MSW R, Bevans, PhD K. The Children's Hospital of Philadelphia Family Partners Program: Promoting child and family-centered care in pediatrics. Patient Experience Journal. 2015; 2(1):50-60. doi: 10.35680/2372-0247.1063.

This Article is brought to you for free and open access by Patient Experience Journal. It has been accepted for inclusion in Patient Experience Journal by an authorized editor of Patient Experience Journal. 
The Children's Hospital of Philadelphia Family Partners Program: Promoting child and family-centered care in pediatrics

\section{Authors}

Amy Kratchman, BA; Darlene Barkman, MA; Kathy Conaboy, BA; Anna de la Motte, MSed; Rachel Biblow, MSW; and Katherine Bevans, PhD 


\title{
The Children's Hospital of Philadelphia Family Partners Program: Promoting child and family-centered care in pediatrics
}

Amy Kratchman, BA, The Children's Hospital of Philadelphia, kratchmana@email.chop.edu Darlene Barkman, MA, The Children's Hospital of Philadelphia, barkmand@email.chop.edu

Kathy Conaboy, BA, The Children's Hospital of Philadelphia, conaboyk@email.chop.edu

Anna de la Motte, MSed, The Children's Hospital of Philadelphia, delamottea@email.chop.edu

Rachel Biblow, MSW, The Children's Hospital of Philadelphia, biblow@email.chop.edu

Katherine Bevans, PhD, The Children's Hospital of Philadelphia, bevans@email.chop.edu

\begin{abstract}
Involving Family Advisory Councils in decisions that impact pediatric healthcare demonstrates hospitals' commitment to child- and family-centered care. Yet, reliance on advisors as the sole source of family input has several limitations: infrequent meetings impedes the council's capacity to address emerging concerns in a timely manner; feedback obtained from a small number of highly-engaged family members may not represent the perspectives of "typical" patients and families; advisors provide feedback in a reactive manner and are generally not equitably involved in problem identification or the initial development of solutions. In recognition of the need to strengthen and advance family partnerships, the Children's Hospital of Philadelphia made significant structural and operational changes to advance and expand the family centered care model. The Family Partners Program, a component of the broader family centered care portfolio, is a centralized institution-wide resource that enables practitioners, researchers, and healthcare leaders to collaborate with trained family representatives. This paper describes the Family Partner Program infrastructure; approaches to recruiting, onboarding, training, and mentoring parents and caregivers; and the many ways that Family Partners promote the core principles of child- and family-centeredness in clinical care, quality improve, and research contexts.
\end{abstract}

\section{Keywords}

Patient and family advisory councils, pediatrics, family centered care, patient experience

Child and family-centered pediatric healthcare systems authentically and equitably involve children and their caregivers in decisions that impact their health outcomes. ${ }^{1-4}$ The Children's Hospital of Philadelphia (CHOP) has long engaged patients and families in efforts to improve children's health and healthcare. The institution's commitment to family-centered care (FCC) is grounded in the understanding that each child is inextricably tied to a family system, the entirety of which is impacted by a member's illness and contributes to his or her healing. Patients and families are experts in themselves and their loved ones. Thus, the optimization of healthcare safety, effectiveness, experiences, and efficiency can only be achieved through collaboration with patients and families. Further, the continual discovery and implementation of the best healthcare approaches requires that families are fully engaged agents for change. $2,4,5$

One of CHOP's institutional goals is to integrate the principles of FCC into all aspects of the healthcare delivery system. The system strives to ground its full array of services in mutually beneficial partnerships among patients, families, practitioners, scientists, and healthcare leaders.

CHOP is committed to the following FCC principles:

- Honor patient and family knowledge, perspectives, and choices

- Engage in open and honest communication with patients and families including disclosure of unbiased information

- Encourage patients and families to participate in decision-making at the level they choose

- Collaborate with patients and families on policy and program development, execution, and evaluation

Established in 1994, the CHOP Family Advisory Council (FAC) is a rotating committee of approximately 50 people comprised of parents/caregivers, as well as CHOP providers and other staff members who share their expertise in support of CHOP's FCC objectives. Monthly FAC meetings provide CHOP employees with opportunities

Patient Experience Journal, Volume 2, Issue 1 - Spring 2015

C The Author(s), 2015. Published in association with The Beryl Institute and Patient Experience Institute

Downloaded from www.pxjournal.org 
to obtain family input on specific projects, policies, or programs. Notable FAC accomplishments include informing the development of educational materials that promote FCC and the redesign of physical space in the hospital to better meet family needs. In 1999, the CHOP Youth Advisory Council (YAC) was established to provide opportunities for patients themselves to inform organizational decisions. The YAC is comprised of approximately 15 patients aged 11-18 years. YAC members have enhanced patient experiences by suggesting modifications to patient menus and ageappropriate entertainment options for children and teens. They also informed the development of driver safety programs and the design of a recently constructed ambulatory care center.

Notwithstanding the advisory councils' accomplishments, the frequency of council meetings (usually monthly) limits opportunities for obtaining YAC/FAC feedback, which is especially problematic for time-sensitive projects. Another limitation is that advisory councils' feedback reflects the perspectives of a relatively small number of parents and youth who may have limited knowledge of the healthcare needs and experiences of some patient/family subgroups. Councils' size constraints also provide few opportunities for parents and youth to contribute to healthcare system improvement. In addition, FAC and YAC members are generally asked to provide feedback about policies and programs in a reactive manner. That is, they review policies and programs that have been conceived, planned, and sometimes even developed without sufficient family and youth input.

The provision of FCC requires that patients and families are proactively involved "early and often" in the identification of high priority initiatives and in program planning, initiation, and monitoring. Lastly, whereas advisory councils have historically focused on the operational aspects of healthcare (e.g., patient flow, parking, meal offerings), FCC-focused systems should enable patients and families to inform the full array of policies and programs that impact their healthcare. Thus, to fully integrate FCC into the full range of healthcare system activities, it is important to move beyond the advisory model and to establish partnerships with patients and families that proactively inform the planning, delivery, and evaluation of hospital operations, clinical care, quality improvement, and research. As FCC and patient/family engagement frameworks evolved, CHOP leaders recognized the need to strengthen the institution's family partnerships. In response, structural support and resources were provided to promote a hospital-wide, FCC model.

\section{The Family Partners Program Infrastructure}

The Family Partners Program is positioned within the Department of Social Work \& Family Services. Its mission is to integrate the patient and family voice into every aspect of healthcare so that patients and family members are partners in providing the best, safest care possible.

The Family Centered Care Manager leads the program. A Program Coordinator serves as the primary point of contact for parent volunteers. There are three full-time Family Consultants, paid hospital employees who originally acted as volunteers and participants in the Family Partners Program. The Family Consultants contribute to numerous FCC initiatives, but their primary function is to oversee the Family Partners Program, an innovative system-wide approach to broadening and improving the implementation of FCC in every aspect of the healthcare delivery system.

The Family Partners Program was created as a centralized institution-wide resource that enables CHOP practitioners, researchers, and healthcare leaders to collaborate with trained and supported family representatives. The Family Partners are parents or others caregivers of a child who is or has been cared for at CHOP. They volunteer in a variety of ways to ensure that family perspectives inform the institution's clinical care, operations, quality improvement, and research. The program provides the infrastructure and other resources needed to recruit, engage, prepare, deploy, and support the Family Partners. The Family Consultants "match" Family Partners to specific projects based on their personal experiences, expertise, readiness to contribute, and preferences.

\section{The Family Centered Care Approach}

Family Partner Recruitment. Prospective Family Partners are often referred to the program by medical staff or the CHOP Office of Feedback. Others selfrefer after learning about the program online (http://www.chop.edu/service/family-centeredcare/family-centered-care.html). Whereas prospective Family Partners were once required to submit a formal application as the initial step toward program participation, they are now encouraged to contact the Family Centered Care Coordinator directly by email or telephone to learn more about the program. This change was instituted for several reasons. First, the written application reduced the involvement of family members with less formal education or career training, many of whom were reluctant to submit a formal résumé-like application. In comparison, the initial personal contact has led to a Family Partners group that better represents CHOP's diverse patient 
population. Second, some prospective Family Partners interpreted submission of the written application as an automatic acceptance into the program. Parents described feeling misled and frustrated when they were subsequently asked to interview for a position. Third, compared to a written application, the personal telephone or email contact better embodies the program's desired culture, which includes:

- Open, honest, and supportive communication

- High degree of staff accessibility

- Transparency of program policies and procedures;

- Clearly-defined program goals

During the initial telephone call with the candidate, the Program Coordinator describes the various roles that Family Partners play in the promotion of FCC. In addition to providing the candidate with preliminary information about the program, the call provides an opportunity for the Program Coordinator to learn about the candidate's experiences, skills, and resources that may enable her to contribute as a Family Partner. Next, the candidate is invited to an in-person meeting with the Program Coordinator and a Family Consultant. During this meeting, the Family Consultant describes the program's mission, philosophy, activities, requirements, and benefits. This information enables candidates to make an informed decision about their readiness, willingness, and capacity to contribute to the program at the present time. Candidates are additionally asked to share their child's healthcare experiences and their reasons for joining the program.

After the in-person meeting, most candidates proceed to the next stage of the onboarding process. A small number of candidates withdraw from the program because of schedule conflicts or because of insufficient time to meet program requirements. Other conflicts include candidates who display a high degree of emotional vulnerability during the interview, or candidates who express a motivation for joining the Family Partners that may be misaligned with the program's mission. In these instances, the program staff carefully considers how to proceed with the candidate.

Emotional Vulnerability. Sometimes parents' emotional response to questions involving their child's health and healthcare indicates that Family Partner activities may overwhelm their coping or healing capacities. When this occurs, a Family Consultant openly shares these concerns with the parent and describes the program's approach to offering vulnerable parents opportunities to contribute in ways that are likely to minimize the re-experience of stress and trauma associated with a child's illness.
Importantly, emotionally vulnerable parents are not excluded from the program. Instead, they are offered opportunities to increasingly engage in the program over time with special assistance and support from a Family Consultant.

Sometimes candidates who appear emotionally vulnerable insist that they are ready to contribute to the Family Partners Program. In these instances, Family Consultants may accompany a parent as they observe a new employee orientation session during which experienced Family Partners share their personal stories as a vehicle for teaching about FCC principles (further described below). After observing the presentation together, the Family Consultant encourages the candidate to reflect on her emotional reaction to the presentation and consider whether she is ready to take on a similar role. Once parents join the program, the pace with which they progress toward more advanced Family Partner roles and responsibilities is informed by their emotional readiness.

A practitioner who cared for her son before he passed away referred Jackie to the program. Three months after her son's death, Jackie contacted the program Coordinator and expressed an interest in volunteering as a Family Partner. During her initial meeting with a Family Consultant, Jackie became very emotional each time she spoke about her son. The Family Consultant openly expressed her concern for Jackie, noting that some Family Partner activities elicit strong emotional reactions especially among grieving parents. The Consultant suggested that Jackie attend a presentation given by another Family Partner to gange her own readiness to engage in similar activities. The Family Consultant accompanied Jackie to the presentation. Afterwards, Jackie told the Family Consultant that she was not yet ready to share her family's story as the Family Partner had. Since then, Jackie has remained engaged with the program by periodically providing feedback on written communication intended for families. Recently, she began working with a Family Consultant on developing a presentation that she will deliver at an upcoming new employee orientation session.

Misaligned Missions. Sometimes a candidate's primary motivation for joining the Family Partners is inconsistent with the program's mission and goals. In these instances, a Family Consultant will discuss this concern with the candidate. Together, they explore whether the parent's desire to affect change in the healthcare system can be gratified through participation in the Family Partners program.

Mrs. Smith was self-referred to the Family Partners 
the healthcare system's awareness of her child's rare condition. She met with a Family Consultant who reviewed the program activities. The Consultant emphasized the program's orientation toward promoting the core principles of FCC. Following these discussions, Mrs. Smith told the Family Consultant that she did not think she could accomplish her goals through participation in the Family Partners program. Following this decision, the Family Consultant arranged a subsequent meeting during which they identified a national advocacy agency focused on her child's condition. Mrs. Smith is now an active contributor to the advocacy agency.

Onboarding and Orientation. New Family Partners are assigned a Family Consultant who acts as a mentor, supporting them for as long as they are involved in the program. At this stage, the Family Consultant assists the Family Partner in navigating the onboarding and orientation process. New Family Partners are required to attend a two-hour orientation session that provides a 3-part overview of program policies, requirements, and opportunities:

1. Family Consultants review the core FCC concepts using illustrative examples of the principles being upheld or violated in various hospital contexts.

2. Experienced Family Partners describe the many roles they play across a wide range of hospital settings (described below).

3. New Family Partners are introduced to the practice of family story telling as a means of demonstrating the principles of FCC (further described below).

Family Partners are provided with a "new member training guide," which provides detailed information about program policies, roles and expectations, and activities.

Institutional requirements. To ensure the protection of CHOP patients and families, the Family Partners are required to:

1. Obtain child abuse clearances

2. Pass criminal background checks

3. Provide records of current immunizations

4. Complete a series of online training courses on topics such as patient privacy, the Health Insurance Portability and Accountability Act (HIPAA), fire safety, and responding to medical emergencies.

Once Family Partners meet these requirements, they are issued a security badge and email address, both of which are needed to navigate the CHOP system. The completion of this intensive onboarding process is required to maintain patient confidentiality and safety. It also contributes to a sense of true inclusion for the Family Partners. Completion of the onboarding process signifies that they have gained institutional trust, recognition, and legitimacy as a valued partner in the hospital's efforts to meet its FCC objectives.

Mentoring. To the degree possible, Family Partners are matched with a Family Consultant with whom they share a common experience (e.g., their children have a similar medical condition, or have received treatment in the same clinic; they have similar FCC priorities).

Family Consultants provide their Family Partner with the resources, knowledge, and emotional support they need to participate in a variety of activities including speaking at hospital events, reviewing documents and policy changes, and contributing to research or quality improvement projects. The primary role of the Family Consultant is to ensure that the Family Partner feels supported and prepared to contribute.

Preparation. For each activity or task, Family Consultants use a variety of strategies to help the Family Partner prepare for a wide range of tasks and activities. Preparation includes helping the Family Partner to better understand the cultural norms and expectations that they will encounter in different contexts, and in their interactions with unique groups of healthcare professionals. Specific preparation strategies are described below.

Modeling. Some activities may be completely new to the Family Partner. In this case, modeling is an important technique for familiarizing the Family Partner with the new task. If a Family Partner is preparing to give a presentation of their personal story, they are encouraged to observe a more experienced Family Partner's presentation before taking on the role of presenter. Family Consultants may also model the Family Partner's story for them, emphasizing the importance of delivery (e.g. including pauses, emphasizing the FCC principles as they arise in the story.)

Family Consultants use their own experiences to help provide context for Family Partners who are completing an activity for the first time. When Family Partners are asked to give a public presentation, the Family Consultant helps to define the setting and audience that will be present, so that the Family Partner can properly tailor the content of the presentation. If a Family Partner is attending a committee meeting for the first time, the Family Consultant will provide information about other committee members, as well as the structure of a typical meeting. 
Janet was asked to join two committees in the hospital. She was a seasoned speaker and Family Advisory Council member, but never served as the family voice on a hospital committee. In advance of the meeting, Janet expressed concerns about not having clinical expertise and feeling "out of her element." In order to address these concerns and increase her comfort in participating at this meeting, it was essential for the team to inform of her of who would be at the table, why they were gathering and the contributions that she would be able to make. It was further emphasized that while she was not a clinician at CHOP, she was an expert in her child and her child's healthcare experience at the hospital. Once she started to present ber feedback in the meeting, she realized the committee members valued everything that she was sharing and looked to her at each meeting to provide the critical family voice to their work.

Support and Review. $\square$ Family Consultants are present during the presentations and committee meetings of new Family Partners. Similarly, if a Family Partner is assuming a new position or task, the Family Consultant is present to assist in the transition. Together, the Family Consultant and Family Partner review the expectations of the new role, and prepare for activities and tasks required of the Family Partner. Close observation allows the Family Consultant to assess the readiness of the Family Partner and depending on the task, make final suggestions and adjustments.

Debriefing. $\square$ Although it is not always possible to do so directly after an event, Family Consultants provide Family Partners with prompt feedback after presentations and the completion of other activities. The debriefing process serves multiple functions. First, it allows the Family Consultant to assess the emotional state of the Family Partner (e.g. inquire about an occurrence during a presentation that might have triggered an emotional response). Second, debriefing gives the Family Consultant and Family Partner time to assess the presentation and discuss successes and areas for improvement.

\section{Family Partner Activities}

As models of FCC have evolved so too have opportunities for Family Partners to impact CHOP projects and policies implemented in a variety of hospital contexts. Family Partners' activities are mapped to a "continuum of engagement," ranging from those that require occasional contributions (e.g., document review) to the full-time leadership position held by Family Consultants. The specific requirements, tasks, and activities associated with each level of engagement are presented in Table 1. Below is a description of the most common activities and roles filled by the Family Partners.

Document review. Family Partners provide feedback on the degree to which written communication, policies, and practice guidelines support the core principles of FCC. For example, Family Partners are commonly asked to review hospital and clinic-specific brochures, letters to families from practitioners and researchers, and educational materials written for families. In their reviews, Family Partners consider whether documents are understandable (if intended for family distribution), respectful, honest, and encouraging of open family-CHOP communication. Document review is an exercise in which the Family Partners use their own experiences and understanding of the FCC principles to produce hospital materials that are familycentered.

Documents are originally submitted to the program Coordinator. The Coordinator forwards the document to a number of Family Partners, so that it is filtered through individuals with varied backgrounds and hospital experiences. All feedback is reviewed by the Family Consultants before final submission. This process is used by the Family Consultants as a teaching moment for new Family Partners; the feedback given allows Family Consultants to assess the Family Partner's application and understanding of the FCC principles.

Advisory Councils. Family Partners serve on the Family Advisory Council (FAC) and as members of specialty advisory teams that focus on specific diagnoses or healthcare experiences. Whereas the FAC generally focuses on system-wide programs and policies, specialty advisory councils provide guidance on issues that pertain to specific patient populations or healthcare experiences. For example, the Autism Family Partners contributed to the development of parent training material intended to prepare families with autistic children for invasive medical procedures such as an IV placement.

One representative from each specialty advisory team serves on the institution-wide FAC. This practice simultaneously supports the institution's need for specialized Family Partner expertise and helps to facilitate communication and co-learning about successful FCC practices across the specialty teams. In this sense, the successful practices of respective teams can be used to balance and inform the difficulties faced by other FAC specialty branches.

Family Partner Speakers. Family Partner Speakers use their personal stories as a framework for educating practitioners, researchers, and healthcare leaders about 
FCC principles and methods. Speakers present at new employee orientation sessions, system-wide meetings, community events, and as guest speakers at the University of Pennsylvania Schools of Medicine and Nursing. The stories are designed to reflect FCC themes such as open and honest communication, shared decision-making, and collaboration. For many, particularly new employees, the Family Partners' presentations provide a first-time introduction to the FCC model. 'Emily's Story' is an example of one Family Partner's story structured to highlight key FCC principles. Throughout the description of her family's healthcare interactions, the Family Partner illustrates the importance of 'information sharing' and 'respect and dignity' (See Appendix).

Family Consultants provide a great deal of guidance and oversight to Family Partners as they develop and refine their family stories. Special attention is given to the language of the story, so that the feedback included has a constructive and non-accusatory tone. Family Partners are encouraged to include and describe positive healthcare experiences so that these may be emulated. Any revisions to the story suggested by Family Consultants are made at the discretion of the speaker. It is essential to ensure that the integrity and authenticity of a family story is never compromised.

For many parents, presenting their child's story amplifies personal vulnerability, causing them to reexperience intense emotions, and undermining their self-efficacy as patient and family representatives. Thus, Family Consultants are highly attuned to the Family Partners' emotional states as they develop and deliver their presentations. As mentioned above, Family Consultants attend the Family Partner presentations to offer support and feedback and to debrief with the Family Partner about the experience.

Committee Membership. Family Partners serve on hospital-wide committees such as the Patient Safety Committee. They rely on their personal experiences and expertise as a parent to provide important input and feedback to the committee. Committees hoping to include the family voice in their meetings contact the program Coordinator. The program Coordinator collaborates with the Family Consultants to identify Family Partners whose expertise aligns with the needs of the committee. Attending committee meetings in the company of hospital leaders can be an intimidating experience. To prepare Family Partners before committee meetings, Family Consultants meet to review the agenda, identify people who are likely to attend the meeting, and describe the committee's culture and expectations for its members.

Family Centered Grand Rounds. The hospital sponsors quarterly rounds designed to provide practical understanding and tactical resources to improve the daily implementation and practice of FCC behaviors. Family Partners have been invited on multiple occasions to present at FCC Grand Rounds. As an avenue for continuing education within the hospital, Family Partners collaborate with nurses, physicians and other hospital staff to offer a family-centered perspective on issues such as bedside rounds. Presentations often include scenarios in which clinicians are asked to actively engage and suggest their own strategies for interacting positively with caregivers.

Quality Improvement Teams. Family Partners provide the family perspective on quality improvement teams throughout the hospital. Teams that want to include a Family Partner as an advisor contact the program Coordinator.

A quality improvement team organized around the
issue of surgical flow contacted the Family Partners
Program Coordinator to include a parent as an
advisor. The team primarily viewed surgical flow as a
clinical concern, limiting the expectations for parent
involvement. The Family Consultant's evaluation of
hospital signage and admission procedures, however,
led to substantial surgical flow improvements. By
bringing to light the numerous registration barriers
experienced by parents, the Family Consultant
illustrated to the team the importance of including the
family perspective.

Family Partners in Research. A commitment to family centered-care extends to the program's involvement in research. These partnerships provide families with an understanding of how research contributes to the evaluation and creation of new interventions and treatments, and in turn ensures that research is driven by the priorities of families. Family Consultants have acted as co-investigators, working with the research team from the beginning of the project. The Family Partners are also asked to serve on research advisory groups, meeting several times throughout the project to provide feedback on a variety of issues, including study design, consent and data interpretation.

\section{The Family Partners Program Operating Principles}

As described above, Family Partners contribute to a wide range of activities. They participate in one or more activity according to three programmatic operating principles:

1. Aligning expertise, experiences, and interests. The effectiveness of the Family Partners program is 
based on informed decisions that best match individual's expertise and experiences with opportunities for involvement. This includes obtaining a thorough understanding of the strengths of each candidate as they are asked to complete early tasks (e.g. reviewing hospital policy), observing candidates during the presentation of their personal story, and listening to the interests expressed by prospective Family Partners during the onboarding process. Although an incoming Family Partner may have experience speaking in front of large groups, they may be more interested in reviewing hospital documents, or serving on a committee. As such, the program includes a range of options for family participation based on interest, time commitment and experience.

The recruitment process allows the team to have a more comprehensive understanding of a Family Partner's past experiences. Familiarity with the Family Partner's personal story allows the team to suggest roles or projects that align with her unique background. When committees interested in including the family perspective contact the Family Partners group, Family Consultants are able to use this knowledge to contact the partners who will likely be good candidates for the position. For example, a workgroup created around IV access contacted the members of the group to request a family representative. The team was able to confidently recommend a parent qualified for the position due to her daughter's inpatient experience with difficult intravenous line placement. Sharing her daughter's experience with the workgroup led to the creation of helpful strategies for staff to better partner with families.

2. Mobility within the Program. The engagement continuum is designed to enable movement amongst the various aspects and opportunities dependent upon an individual Family Partners' experience, sense of empowerment, skill, motivation, and personal circumstances. By treating training as a continuous process, Family Consultants are able to closely observe the growth of the Family Partners. Careful training and mentoring creates a reliable pool for filling formalized roles as they become available.

Recently, the growth of the Family Partners Program led to the development of a third Family Consultant position. The consultant role is a paid position that requires a full-time commitment. The Family Partners filling the other two consultant positions knew that the candidates for the third seat would need to have a thorough understanding of the Family Partner mission and training process. A group of Family Partners that had demonstrated leadership and the ability to commit to a more demanding role was recruited for the interview process.
Mobility is also increased by the exposure of the Family Partners to the wide variety of roles filled by other members. Through the observation of other opportunities for involvement Family Partners who are ready to take on more demanding positions are aware of the options open to them. As the status of their child's health improves, or as they gain experience, many Family Partners become active in driving their own upward mobility within the group.

3. Flexibility. Since many families have a chronically ill child, it is essential to exercise flexibility in the placement of Family Partners. A crucial component of the program is the ongoing assessment of Family Partner readiness. Readiness can change over time, regardless of how long a Family Partner has been involved in the program. A Family Partner who is actively engaged in several committees may have to reduce involvement due to a health status change. The program allows Family Partners the option to take the necessary space and time away from specific work, while still maintaining membership and potentially being utilized in a different capacity.

Pete is an active and involved Family Partner, whose
daughter's chronic condition worsened, leading to a
lengthy hospital stay. During the admission, Pete
quickly realized that he needed to take a step back
from the committee he was participating on because be
recognized he was becoming too emotional and no
longer able to communicate effectively. He approached
his mentor to discuss the concern and was able to
transition off of this committee until his daughter's
condition improved.

While it is the responsibility of the Family Consultants to monitor the emotional impact of the commitment made by the Family Partners, the decision to leave or continue one's role within the group is a personal choice. By leaving the final decision to the Family Partner, they are allowed to use the support of the group, while still acting autonomously.
Yolanda's daughter was treated at the hospital for intractable seizures that resulted in significant developmental disabilities. At the same time, Yolanda was undergoing treatment for her own serious medical condition. The team was concerned that she was going to become overwhelmed. Yolanda insisted, however, that she wanted to and would be able to continue her work in the program. Despite the juggling of her own condition and the condition of her daughter, Yolanda continues to be one of our most active family partners working across three domains: research, safety and quality and improvement. She was grateful that the group hadn't prevented her from working when she was sick, because the work gave her a sense of purpose 
during a difficult time.

\section{Summary}

This paper describes the Family Partner Program infrastructure; details the processes of recruitment, onboarding, training and mentoring; and provides examples of Family Partners' contributions to promoting child- and family-centered care in a variety of healthcare system contexts. The program's partnership approach addresses many of the limitations of family advisory councils. By including Family Partners in research groups, hospital committees and other teams, parents are able to inform the planning, development and delivery of programs and research instead of being limited to providing feedback reactively.

We believe that the program is successful in preparing active and empowered patient and family contributors because of its steadfast commitment to several operating principles. The program uses the strengths, experiences and interests of the Family Partners to match them with tasks and roles that they are both capable and interested in filling. Further, the program promotes flexibility and mobility by allowing Family Partners to adjust their level of engagement as their child's health status changes, or as they gain experience and exposure to other opportunities for participation. The Family Partners Program is a work in progress, but illustrates some of the key features that we believe enhance family centeredness in health care. As this program (and others like it) evolve, research on the programs' impact on child and family health care experiences and outcomes will be essential for identifying program elements that contribute to their success.

\section{References}

1. Johnson B, Abraham M, Conway J, et al. Partnering with Patients and Families to Design a Patient- and Family-Centered Health Care System.

2. Bethesda, MD: Institute for Patient- and FamilyCentered Care; 2008.

3. Gabriel SE, Normand ST. Getting the methods right: The foundation of patient-centered outcomes research. N Engl J Med. 2012; 367(9):787-90.

4. National Quality Forum (Aug 2014). Priority setting for healthcare performance measurement: Addressing performance measurement gaps in person-centered care and outcomes.

http://www.qualityforum.org/Publications/2014/ 08/Priority_Setting_for_Healthcare_Performance _Measurement_Addressing_Performance_Measu re_Gaps_in_Person-
Centered_Care_and_Outcomes.aspx. Published August 15, 2014, Accessed January 25, 2015.

5. Institute of Medicine. Crossing the Quality Chasm: $A$ New Health System for the $21^{\text {st }}$ Century. http://www.iom.edu/ /media/Files/Report $\% 20$ Files/2001/Crossing-the-QualityChasm/Quality \%20Chasm\%202001\%20\%20repor $\mathrm{t} \% 20$ brief.pdf. Published March 1, 2001, Accessed January 25, 2015.

6. Institute of Medicine. Patients Charting the Course: Citizen Engagement and the Learning Health System. Washington, DC: National Academies Press; 2011. 


\section{Table 1. Family Partner Roles and Activities by Levels of Engagement}

\begin{tabular}{|c|c|c|c|}
\hline $\begin{array}{c}\text { Levels of } \\
\text { Engagement }\end{array}$ & Training \& experience & Role characteristics & Activities \\
\hline Contributors & $\begin{array}{l}\text { Training and onboarding } \\
\text { may be underway or } \\
\text { complete }\end{array}$ & $\begin{array}{l}\text { - Acts as representative of families at } \mathrm{CHOP} \\
\text { - The large number of Contributors ensure provision } \\
\text { of diverse feedback } \\
\text { - Allows parents to contribute without making a very } \\
\text { - } \text { - Time commitantial time commitment is flexible } \\
\text { - Family Consultants review all work and provide } \\
\text { specific feedback }\end{array}$ & $\begin{array}{l}\text { - Reviews documents } \\
\circ \quad \text { Letters to families } \\
\circ \quad \text { Signage for inpatient or outpatient facilitates } \\
\text { - Reviews proposed policy and practice changes } \\
\circ \quad \text { Written policies (e.g., limited visitation during } \\
\text { flu season) } \\
\circ \quad \text { Practice guidelines (e.g., encouraging family } \\
\text { members to maintain clutter free in-patient } \\
\text { rooms to reduce infection) } \\
\text { - Research participants (e.g., focus group members) }\end{array}$ \\
\hline Advisors & $\begin{array}{l}\text { Training and onboarding } \\
\text { complete }\end{array}$ & $\begin{array}{l}\text { - Has identified a population or hospital location } \\
\text { about which they can provide targeted feedback } \\
\text { (e.g., Parents of children with Autism, parents of } \\
\text { children served in primary care settings) } \\
\text { - Contributes approximately } 10 \text { hours per month } \\
\text { - Always accompanied by Family Consultant while } \\
\text { presenting or attending meetings. } \\
\text { - Family Consultants review most work and provide } \\
\text { specific feedback as needed. }\end{array}$ & $\begin{array}{l}\text { - All Contributor activities }+ \\
\text { - Review documents that pertain to practices and } \\
\text { policies that impact a specific target population } \\
\text { - May serve on diagnosis- or clinic-specific committees } \\
\text { - Could serve on CHOP's Family Advisory Committee } \\
\text { - Presents their family story to illustrate Patient- and } \\
\text { Family Centered Care principles (e.g., new employee, } \\
\text { intern, and resident orientation, Nursing Education, } \\
\text { etc.) }\end{array}$ \\
\hline Collaborators & $\begin{array}{l}\text { - Training and onboarding } \\
\text { complete } \\
\text { - Experience reviewing } \\
\text { documents } \\
\text { - Experienced committee } \\
\text { members (e.g., Family } \\
\text { Advisory Council) } \\
\text { - Evidence of capacity to } \\
\text { provide direct feedback } \\
\text { to hospital leaders, } \\
\text { clinicians, and } \\
\text { researchers }\end{array}$ & $\begin{array}{l}\text { - Skilled at giving tailored feedback that resonates } \\
\text { with specific stakeholder groups (e.g., hospital } \\
\text { administrators, physicians, parents, researchers) } \\
\text { - "Specializes" in a specific domain of patient- and } \\
\text { family-centered work (e.g., research, quality } \\
\text { improvement, patient safety) } \\
\text { - Contributes approximately 15-20 hours per month } \\
\text { - Sometimes accompanied by Family Consultant } \\
\text { (e.g., presenting their family story to the Hospital } \\
\text { Board of Trustees) } \\
\text { - Family Consultants provide mentorship as Core } \\
\text { Team Members take on new activities and greater } \\
\text { responsibility } \\
\text { - Mentorship focused on the development of } \\
\text { independence and progressing toward becoming a } \\
\text { Family Leader }\end{array}$ & $\begin{array}{l}\text { - All Advisor activities + } \\
\text { - May serve on institution-wide committees (e.g., } \\
\text { Patient Safety, Infection Prevention) } \\
\text { - May contribute to quality improvement teams (e.g., } \\
\text { contribute to implementation of PDSA cycles) } \\
\text { - Makes educational videos for staff, parents, and } \\
\text { - Matients } \\
\text { - Assist in training new Family Partners }\end{array}$ \\
\hline
\end{tabular}


Promoting child and family-centered care in pediatrics, Kratchman et al.

\begin{tabular}{|l|l|l|l|}
\hline $\begin{array}{l}\text { Leaders } \\
\text { (Family } \\
\text { Consultants) }\end{array}$ & $\begin{array}{l}\text { - Paid employees } \\
\text { Multiple years experience } \\
\text { as a Family Partner }\end{array}$ & $\begin{array}{l}\text { - Skilled at supervising and mentoring Early } \\
\text { contributors and Family Partners at each level of } \\
\text { engagement } \\
\text { - Contributes approximately 24-40 hours per week }\end{array}$ & $\begin{array}{l}\text { - All Advisor activities + } \\
\text { - Supervises and mentors all Early Contributors and } \\
\text { Family Partners } \\
\text { - Provides graduated mentorship as Family Partners } \\
\text { advance through the program } \\
\text { Recruits and on-boards Family Partners } \\
\text { - Conducts and coordinates Family Partner training } \\
\text { - Assigns Early Contributors and Family Partners to } \\
\text { activities } \\
\text { - Co-chairs the Family Advisory Council } \\
\text { - May serve as co-Investigators in research }\end{array}$ \\
\end{tabular}




\section{Appendix}

"My daughter Emily was born in October of 2004. I had no problems during my pregnancy and Emily was born small but healthy. From the moment we came home Emily had a very difficult time taking her bottle. She would take a few sips of her formula and start screaming in pain. During an early visit with our pediatrician I mentioned what I had been observing. Familiar with our son's difficulty with reflux, our pediatrician sent us to our CHOP GI doctor. Our GI examined Emily and told us that she probably had a bad case of reflux like my son and she would start her on medicines. Because of our son's condition we felt very comfortable with that. Unfortunately, she kept getting worse. At a month old she could take no more than half an ounce of a bottle. I could hear the formula hitting her stomach and she would cry in pain.

One night I decided to take her temperature thinking that maybe this was all due to an illness. When the pacifier thermometer beeped I looked down I saw that Emily had stopped breathing. I went in to panic mode, called out to my husband to call the pediatrician, and worked at getting Emily to breathe again. While he was on the phone with the doctor, she stopped breathing again, and the doctor told us to go straight to our closest ER. By the time we arrived at the ER, Emily was looking so nice and rosy that the doctors kept asking us if we were sure she stopped breathing. I called our CHOP GI doctor to ask if this was due to her GI problems. Our CHOP GI doctor collaborated with the team at the local hospital to run a series of tests. The tests showed that Emily did have a bad case of reflux that had caused her to stop breathing. In response the doctors changed her medications and sent us home with an apnea monitor.

Emily was readmitted to the hospital 10 days later with a fever. While waiting for the tests results to come in I was feeding Emily, and she started to cry in pain. I quickly called the doctor and nurse over so they could see what was going on. The nurse patted me on the back and said, "Mom, you just need to relax and your baby will take her bottle." I remember thinking that this was my third child, and I that I knew how to feed a baby. When she was released, I took her to our CHOP GI doctor's office for a visit. Our doctor sat with us, and had me feed Emily in front of her so she could see for herself what happens. She observed carefully and spoke about how Emily was slowly slipping off of the growth chart and was in danger of malnutrition.
Together we came up with a new plan for Emily. We would try to get Emily to gain weight by feeding her every hour coupled with a fat supplement in her formula.

After two weeks Emily had slipped lower on the growth chart and was only 8 pounds by three months of age. Our doctor said she thought it was time to intervene further. She discussing placing an NG tube down Emily to pump the food in to her and take the pressure off of oral feeding. I must have looked at the doctor with such horror, because she said to me, "I don't want you to think this is a punishment. This is nothing you did. This is nothing Emily did. We just have to help her get the nutrition she needs." That extra time she took to explain that to me made me feel much better about placing the tube.

Once Emily had her tube placed and the doctors made sure she was $\mathrm{OK}$ with the formula, it was time for us to be discharged. I was terrified. I was going home with this tube down my daughter's throat and medical equipment that I had to learn to use. The nurse came over to me and said, "We will not send you home until you are $100 \%$ comfortable with the equipment."

Unfortunately things got worse. Emily started throwing up all of her feeds; everything that went down came right back up. Our GI doctor explained to us the next step. They had a G-J tube placed surgically so the food would go directly in to her small intestine. When Emily was discharged she was doing so much better at tolerating her feeds.

At our check-up I remember our doctor being so excited to see the little fat rolls that Emily was finally getting on her legs. I admitted to the doctor that I was happy with her improvement, but also sad over the way our family life had changed. Her feeding pump made it difficult to go anywhere. Understanding the healthcare needs of Emily and my other children, our doctor thought carefully about a new plan. Together we found a research medicine that Emily was able to go on, and I am happy to say that she is now a happy five-year-old who eats all of her meals by mouth."

Lessons learned: "Our concerns were real, and acknowledged as such by our doctor. Our doctor approached each bump in the road carefully and included us in each decision being made. Our doctor was not content in finding a treatment that worked. She wanted a treatment that worked for our family." 